\title{
Outcomes of a Dutch workshop on improvements for the 3Rs in daily practice
}

\author{
Judith van Luijk ${ }^{1}$, Marlies Leenaars ${ }^{1}$, Anne Marie van Dongen ${ }^{2}$, Lilian van der Vaart ${ }^{2}$, \\ and Merel Ritskes-Hoitinga ${ }^{1}$ \\ ${ }^{1}$ SYRCLE (previously 3R Research Centre), Central Animal Laboratory, Radboud University Nijmegen Medical Centre, \\ The Netherlands; ${ }^{2}$ Vaart Innovation and Knowledge Management, Oisterwijk, The Netherlands
}

\begin{abstract}
Summary
This article describes the outcome of a workshop that was held to generate new ideas to improve the use of the $3 R$ principles in science. The participants of the workshop represented Dutch researchers, Animal Welfare Officers, and members of Animal Ethics Committees from various affiliations, including academia, industry, contract research organizations, and knowledge centers in the Netherlands.

The workshop resulted in six diverse consensus statements, which are presented and discussed in this article. The results show that there is no single, straightforward solution to improving the implementation of $3 R$ methods in animal-based research and that further improvement in $3 R$ s practice requires a more multi- and interdisciplinary awareness and approach.
\end{abstract}

Keywords: workshop, 3Rs, laboratory animals

\section{Introduction}

Over the last 50 years, the 3 Rs have been the guiding principles in animal-based research (Russell and Burch, 1959). Even though they are incorporated into the legislation of many countries, it remains difficult to implement the 3 Rs principles in science and to evaluate the effectiveness of $3 \mathrm{Rs}$ implementations (ZonMw, 2011; Ormandy et al., 2009).

In 2009 a survey was conducted by the 3R Research Centre Nijmegen (now SYRCLE) to investigate how professionals in animal-based research (scientists, Animal Welfare Officers, and Animal Ethic Committee members) search for and implement 3Rs methods in daily practice. The results showed that searching for 3Rs methods is perceived as a difficult task (van Luijk et al., submitted; van Luijk et al., 2011). The outcomes of this national survey are comparable to earlier local findings (Leenaars et al., 2009; NC3Rs, 2008) and international studies (NC3Rs, 2008; Fenwick et al., 2011). The majority of the respondents were not familiar with specialized databases and websites for animal science and the 3Rs, although more than 100 such resources are available. Additionally, the proper skills to search these databases were limited. Most information on the 3 Rs that is perceived as useful is retrieved directly from colleagues and through personal communication with other professionals (van Luijk et al., submitted; van Luijk et al., 2011). This is an undesirable situation, as information remains local and may thus restrict the use of new 3Rs innovations.

For this reason a national workshop was organized to investigate potential strategies to improve the implementation of the 3Rs principles in science. The workshop resulted in six consensus statements, which are presented here. The diversity of the statements and outcomes of other (inter)national studies (Smaje et al., 1998;
Brønstad and Berg, 2011; de Boo and Hendriksen, 2005; Engeman and Shumake, 1993; Howard et al., 2009; Lloyd et al., 2008; Reed and Jennings, 2008; Wendel, 2002; ZonMw, 2011; NC3Rs, 2008; Fenwick et al., 2011) make it clear that there is no single, straightforward solution and that further improvement of $3 \mathrm{R}$ use requires a more multi- and interdisciplinary awareness and approach.

\section{Three Rs Workshop}

In 2010 the 3R Research Centre (SYRCLE since February 2012), organized in collaboration with Vaart Innovation and Knowledge, a workshop in the framework of a project funded by the Netherlands Organisation for Health Research and Development (ZonMW): "Three Rs information in practice - national survey on searching, finding, and applying the 3Rs" (project number ZonMW 114000 092). The aim of this study was to gain insight into how researchers, animal welfare officers (AWO), and members of animal ethics committees (AEC) incorporate the 3Rs principles (Russell and Burch, 1959) into their work. This workshop was a follow-up to an earlier survey (van Luijk et al., 2011; van Luijk et al., submitted). The results of the questionnaires showed that there is room for improvement in 3Rs implementation, and especially in how $3 \mathrm{R}$ information is obtained.

Respondents were asked if they were willing to participate in the workshop. A total of 36 respondents agreed and were invited for the workshop, in which 18 participated. Together, the participants represented eight different organizations, including universities, industry, contract research organizations (CRO), and knowledge centers. It was, to our knowledge, the first time in the Netherlands that researchers, AWOs, and AEC members from different organizations were brought together to discuss the current state of affairs on the 3 Rs principles and how to improve the 
use of these principles in daily practice. The aim of the workshop was to delve more deeply into the ideas suggested in the surveys and to formulate and prioritize required actions for a better exchange of 3R knowledge and a more optimal 3R implementation in practice.

Table 1 shows the affiliations of the 18 workshop participants. It should be noted that five participants exerted in daily practice two professional roles: four AWOs and one researcher were or had been a member of an AEC. To avoid a possible conflict between two professional roles, those participants were asked to select the profession they had when filling out the questionnaire for the workshop. The five participants indicated that their main profession was either researcher or AWO.

During the introduction to the workshop, a detailed overview of the survey results was presented. Accordingly, the workshop participants were asked to comment in plenum. Based on this general discussion, the more detailed discussion topics for the afternoon session were formulated.

In order to facilitate more in-depth discussions, the participants were divided into two groups for the afternoon session. The group composition was based on combining various backgrounds and professions, to create two more or less similarly mixed groups. Each group was led by one of the professional discussion leaders of Vaart Innovation and Knowledge Management. In the con- cluding plenary session, the two groups presented and discussed their main points, which together were used as the basis for the formulation of mutual consensus statements.

\section{Consensus statements}

At the end of the workshop the participants formulated six consensus statements, which are described below. Table 2 provides an overview of these consensus statements and includes suggested key players for achieving each goal mentioned. The key players were both suggested by the workshop participants during the workshop and added based on correspondence afterwards. A draft version (in Dutch) of the workshop report was sent out to all participants for approval.

\section{Division of the 3Rs and avoiding use of the term "alternatives"}

In order to address each $\mathrm{R}$ appropriately in its own right, according to the participants, it is advisable to split the 3Rs into "Replacement" and "Reduction and Refinement" (also referred to as "best practice"). Replacement requires an approach different from the application of Reduction and Refinement methods. Replacement methods, for instance, require validation and sometimes even legislative involvement in order to be accepted on a national or international level. Addressing the 3Rs as a

Tab. 1: Affiliations of the workshop participants

\begin{tabular}{|c|c|c|c|c|c|c|}
\hline & Academia & Industry & $\begin{array}{c}\text { Knowledge } \\
\text { Institute }\end{array}$ & $\begin{array}{c}\text { Contract } \\
\text { Research } \\
\text { Organization }\end{array}$ & Other & Total \\
\hline Researchers & 1 & 0 & 3 & 2 & 0 & 6 \\
\hline Animal welfare officers & 4 & 2 & 2 & 1 & 0 & 9 \\
\hline Animal ethics committee members & 0 & 0 & 2 & 0 & 1 & $3^{*}$ \\
\hline
\end{tabular}

* The total number of AEC members was eight, but only three were solely AEC members, the other AEC members were an AEC member as a second profession. Their main profession was an AWO or a researcher and they participated in the workshop as such.

Tab. 2: The consensus statements formulated during the workshop and suggested key players

\begin{tabular}{|ll|l|}
\hline \multicolumn{2}{|c|}{ Consensus statement } & Suggested key players \\
\hline 1. & $\begin{array}{l}\text { Division of the Three Rs and cautious use of the term } \\
\text { "alternatives." }\end{array}$ & All involved in animal based research \\
\hline 2. & $\begin{array}{l}\text { Awareness for Replacement on a higher level and at } \\
\text { earlier stages of research, additionally appointment } \\
\text { of a Replacement expert. }\end{array}$ & $\begin{array}{l}\text { License holders, project leaders, animal ethics committees, } \\
\text { scientific committees/boards within license holding organizations }\end{array}$ \\
\hline 3. & $\begin{array}{l}\text { Bring license holders and funding bodies together for } \\
\text { discussing the topics "transparency" and "responsibility." }\end{array}$ & $\begin{array}{l}\text { License holders, funding bodies (e.g., ZonMw and disease } \\
\text { related funding agencies), government, public }\end{array}$ \\
\hline 4. & $\begin{array}{l}\text { Awareness in education for building the } \\
\text { "proper" attitude and improving implementation of }\end{array}$ & $\begin{array}{l}\text { Dutch association for laboratory animal science (NVP), } \\
\text { National Coordinators of the courses in laboratory animal } \\
\text { science, FELASA }\end{array}$ \\
\hline 5. & $\begin{array}{l}\text { Accessible knowledge exchange: } \\
\text { - (inter)national meetings on animal models } \\
\text { - Publication of "negative" results }\end{array}$ & $\begin{array}{l}\text { Animal care staff and technicians, researchers, AWOs, } \\
\text { research departments, funding bodies, editorial boards } \\
\text { of scientific journals }\end{array}$ \\
\hline 6. & Facilitate and stimulate collaborations (communication). & $\begin{array}{l}\text { NKCA (Netherlands Knowledge Centre on Alternatives), } \\
\text { government, politicians and society }\end{array}$ \\
\hline
\end{tabular}


whole raises the risk that full justice will not be accorded each and all of the 3Rs.

An additional issue concerns the use of the term "alternatives" in the context of communication within the scientific field, as well as with the public at large. In practice, the term " $3 \mathrm{R}$ alternatives" is frequently used, often creating the impression that it refers to genuine replacements. According to some of the participants, Replacement is only a small - and in some fields even negligible - part of the 3Rs. It was suggested that the term "alternatives" be abolished altogether. Clearly, abolishing the term "alternatives" in the scope of Laboratory Animal Science does not seem realistic, since it is a very well established term, dating from the $3 \mathrm{R}$ definition of alternatives by David Smyth (Balls et al., 1995; Smyth, 1978). The image of the "3R alternatives" however, can be addressed. The utility of and need for the 3Rs should be expressed in a more scientific context, alongside the well-known animal-welfare arguments. The workshop participants also expressed their feeling that the current image of the word " $3 \mathrm{R}$ alternatives" is often seen as "dusty." The field of laboratory animal science and its focus on 3R alternatives is therefore often seen as a service or secondary field of research. In order to promote proper science, as well as animal welfare, it is important to provide a clear definition not only of each of the Rs but also of the field of laboratory animal science as a whole.

\section{Awareness of Replacement on a higher level and earlier} stage of research, appointment of a Replacement expert The participants agreed that optimal implementation of each of the Rs requires its own expertise. For questions related to Refinement and Reduction methods an AWO and/or a biostatistician can be approached. According to the results of both surveys and the workshop discussion, however, it is not clear whom to consult for Replacement possibilities (van Luijk et al., 2011; van Luijk et al., submitted). Therefore, the workshop participants suggested the appointment of a local Replacement expert, in a manner similar to the appointment of AWOs in the Netherlands. In order to address each "R," an ideal situation could be a 3R-consultation team including: a Replacement expert, a (bio)statistician, and an AWO.

According to the participants, the timing of addressing each of the Rs is crucial. Ideally, Replacement should be addressed at an early stage and at a high(er) responsibility level in the research chain. In fundamental research the responsibility for Replacement often lies with the researcher. This, however, is not an ideal situation, since the development of Replacement possibilities usually does not lie within the expertise of the individual researcher. In the situation of regulatory testing the implementation of a full Replacement method is even more complex, as it requires participation of multiple institutions and researchers over a longer time period. Therefore, according to the participants, this responsibility should be shifted to (teams at) higher hierarchical levels, such as project leaders, license holders, government, and funding bodies. Only then can the development of Replacement methods be prioritized and achieved by making the necessary resources available.

\section{Bring license holders and funding bodies together to discuss topics on transparency and responsibility}

The debate on openness and transparency in the field of laboratory animal science in the Netherlands has been ongoing for a long pe- riod of time. The lack of transparency is counterproductive in science, as it creates difficulties in data exchange and thus problems in coordination and cooperation of research. Additionally, the lack of transparency raises many critical questions in society and in animal rights groups. From the questionnaires it became clear that there is a need for more data exchange between research institutes (van Luijk et al., 2011; van Luijk et al., submitted). The responsibility for more openness lies primarily with the licensees and funding bodies (e.g., governmental funding and foundations such as the cancer fund and heart and kidney foundation). According to the participants, license holders and funding bodies have the capability and the power to enforce transparency. They can demand the mandatory publication of all results, including the so-called "negative results" (or neutral results). Depending on the circumstances, the degree of openness can be adapted to particular needs: the information from projects can be made anonymous for reasons of personal safety, and information can be temporarily withheld when it concerns a non-competition covenant.

\section{Awareness in education for attitude development and best practicelexperimental design}

In the Dutch course on Laboratory Animal Science (comparable to the FELASA category C course (FELASA, 1995)) the main focus lies on the $3 \mathrm{R}$ principles. This course is compulsory for all researchers and $\mathrm{PhD}$ students who will be involved in animal-based research. Often young scientists attend this course prior to starting their scientific careers. Once they start their own research project, however, important information from this course may be forgotten. Therefore, the workshop participants discussed the idea of a more continuous and possibly obligatory form of education for those involved in animal experimentation to keep knowledge up-to-date. The survey results (van Luijk et al., 2011; van Luijk et al., submitted) showed that "researcher's own motivation" and "a good study preparation" are two of the key factors for implementation of the 3Rs. It was therefore concluded that continuous professional education should focus on building the right attitude and experimental design in order to stimulate the motivation for implementation of 3 Rs methods.

\section{Accessible knowledge exchange}

The current lack of transparency limits other needs within (laboratory animal) science, such as the exchange of knowledge. When planning a new study, it is essential to take into account all other planned or ongoing studies relevant to the research question. In order to stimulate collaborations and prevent unnecessary duplications, it is evident that this information must be shared.

During the workshop a suggestion was made to organize (inter) national meetings focused on animal models to share knowledge and experiences. Similar types of meetings also could be organized per research field (e.g., disease types), and these meetings can easily be organized in combination with already existing (inter) national meetings and conferences. This also allows for more indepth discussions on the pros and cons of the various animal models used in one specific field of research. A second issue addressed during the workshop was the necessity of publishing "negative" (neutral) results. "Negative" or neutral data from animal studies often are not published, due mainly to editorial policies of the jour- 
nals. Nevertheless, this data has scientific value and is essential in preventing unnecessary duplication of studies. Editorial boards of scientific journals can play an important role in facilitating the publication of these negative and neutral results.

\section{Facilitate and stimulate collaborations (communication)} According to the workshop participants, there is a need for management and coordination within the field of laboratory animal science in the Netherlands. Issues such as lack of transparency and competition currently are important factors that limit research cooperation and knowledge exchange. The lively and passionate discussions during the workshop demonstrate that these issues are not easy to resolve. Nevertheless, there is much room and opportunity for improvement. According to the workshop participants, the national coordination and communication should be organized, e.g., by the NKCA (Netherlands Knowledge Centre for Alternatives) in order to define an action plan that identifies, prioritizes, and addresses the actions needed on a national level.

\section{Concluding remarks}

As the results of the workshop and earlier studies have shown, there is no single solution for how to improve the implementation of the 3Rs principles in science. A diversity of themes, such as education (for both new and experienced researchers), multi- and interdisciplinary collaboration, transparency of the decision process for animal-based research, and information/ data exchange have been proposed for further consideration in order to enhance both animal welfare and science.

\section{References}

Balls, M., Goldberg, A. M., Fentem, J. H., et al. (1995). The three Rs: the way forward: the report and recommendations of ECVAM Workshop 11. Altern Lab Anim 23, 838-866.

Brønstad, A. and Berg, A. G. T. (2011). The role of organizational culture in compliance with the principles of the 3Rs. Lab Anim 40, 22-26.

de Boo, J. and Hendriksen, C. (2005). Reduction strategies in animal research: a review of scientific approaches at the intraexperimental, supra-experimental and extra-experimental levels. Altern Lab Anim 33, 369-377.

Engeman, R. M. and Shumake, S. A. (1993). Animal Welfare and the Statistical Consultant. The American Statistician 47, 229 233.

FELASA (1995). FELASA recommendations on the education and training of persons working with laboratory animals: categories A and C. Reports of the Federation of European Laboratory Animal Science Associations Working Group on Education accepted by the FELASA Board of Management. Lab Anim 29, 121-131.

Fenwick, N., Danielson, P., and Griffin, G. (2011). Survey of Canadian animal-based researchers' views on the Three Rs: replacement, reduction and refinement. PLoS One 6, e22478.
Howard, B., Hudson, M., and Preziosi, R. (2009). More is less: reducing animal use by raising awareness of the principles of efficient study design and analysis. Altern Lab Anim 37, 33-42.

Leenaars, M., Savenije, B., Nagtegaal, A., et al. (2009). Assessing the search for and implementation of the three Rs: A survey among scientists. Altern Lab Anim 37, 297-303.

Lloyd, M. H., Foden, B. W., and Wolfensohn, S. E. (2008). Refinement: Promoting the three Rs in practice. Lab Anim 42, 284-293.

NC3Rs (2008). Survey Report 2008 "Views on the 3Rs". http:// www.nc3rs.org.uk/downloaddoc.asp?id=836

Ormandy, E. H., Schuppli, C. A., and Weary, D. M. (2009). Worldwide trends in the use of animals in research: the contribution of genetically-modified animal models. Altern Lab Anim 37, 63-68.

Reed, B. T. and Jennings, M. (2008). Promoting consideration of the ethical aspects of animal use and implementation of the 3Rs. AATEX, Spec Issue 14, 131-135.

Russell, W. M. S. and Burch, R. L. (1959). The Principles of Humane Experimental Technique. London, UK: Methuen.

Smaje, L. H., Smith, J.A., Combes, R. D., et al. (1998). Advancing refinement of laboratory animal use. Lab Anim 32, 137-142.

Smyth, D. H. (1978). Alternatives to Animal Experiments. SAderschot, UK: Scolar.

van Luijk, J., Cuijpers, Y., van der Vaart, L., et al. (2011). Assessing the search for information on Three Rs methods, and their subsequent implementation: a national survey among scientists in the Netherlands. Altern Lab Anim 39, 429-447.

van Luijk, J., Cuijpers, Y., Van Der Vaart, L., et al. (submitted). Assessing the application of the Three Rs: A survey among Animal Welfare Officers in the Netherlands.

Wendel, A. (2002). Do we need a "Chair of alternative methods", and where? ALTEX 19, 64-68.

ZonMw (2011). Opbrengst ZonMw programma's op Vervanging, Vermindering en Verfijning van dierproeven; analyse periode 2001-2011 (Yield ZonMw programs on Replacement, Reduction and Refinement of animal experiments; analysis period 2001-2011). ZonMw.

\section{Acknowledgements}

This project was funded by the ZonMW program, Dierproeven begrensd II (animal-studies limited II), Project No. 114000092. The authors would like to thank all the workshop participants for their input during the workshop and feedback on the workshop report.

\section{Correnspondence to}

Judith van Luijk

SYRCLE

Central Animal Laboratory

Radboud University Nijmegen Medical Centre

PO Box 9101, 6500 HB Nijmegen

The Netherlands

Fax: +31243616375

e-mail: J.vanLuijk@cdl.umcn.nl 